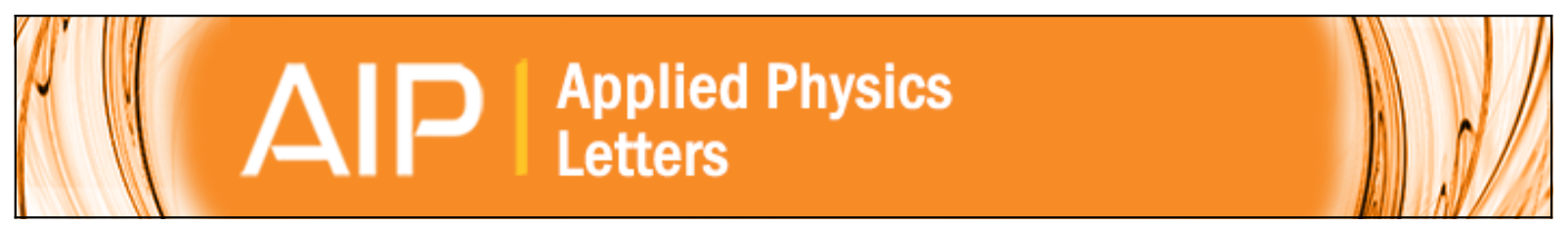

\title{
Single-walled carbon nanotubes based chemiresistive genosensor for label-free detection of human rheumatic heart disease
}

Swati Singh, Ashok Kumar, Shashi Khare, Ashok Mulchandani, and Rajesh

Citation: Applied Physics Letters 105, 213701 (2014); doi: 10.1063/1.4902447

View online: http://dx.doi.org/10.1063/1.4902447

View Table of Contents: http://scitation.aip.org/content/aip/journal/apl/105/21?ver=pdfcov

Published by the AIP Publishing

\section{Articles you may be interested in}

Conducting polymer functionalized single-walled carbon nanotube based chemiresistive biosensor for the detection of human cardiac myoglobin

Appl. Phys. Lett. 105, 153701 (2014); 10.1063/1.4897972

Label-free detection of cardiac troponin-I using gold nanoparticles functionalized single-walled carbon nanotubes based chemiresistive biosensor

Appl. Phys. Lett. 103, 203703 (2013); 10.1063/1.4830223

Nanostructured magnesium oxide biosensing platform for cholera detection

Appl. Phys. Lett. 102, 144106 (2013); 10.1063/1.4800933

Label-free chemiresistive biosensor for mercury (II) based on single-walled carbon nanotubes and structureswitching DNA

Appl. Phys. Lett. 102, 013701 (2013); 10.1063/1.4773569

ZnS nanocrystals decorated single-walled carbon nanotube based chemiresistive label-free DNA sensor Appl. Phys. Lett. 98, 013701 (2011); 10.1063/1.3529951

Want to publish your paper in the \#1 MOST CITED journal in applied physics?

With Applied Physics Letters, you can.

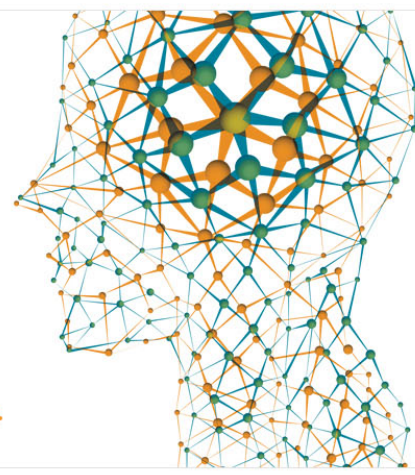




\title{
Single-walled carbon nanotubes based chemiresistive genosensor for label-free detection of human rheumatic heart disease
}

\author{
Swati Singh, ${ }^{1,2}$ Ashok Kumar, ${ }^{1,2, a)}$ Shashi Khare ${ }^{3}$ Ashok Mulchandani, ${ }^{4}$ and Rajesh ${ }^{5, a)}$ \\ ${ }^{1}$ CSIR-Institute of Genomics and Integrative Biology, Mall Road, Delhi 110007, India \\ ${ }^{2}$ Academy of Scientific and Innovative Research (AcSIR), New Delhi, India \\ ${ }^{3}$ National Centre for Disease Control, Sham Nath Marg, Delhi 110054, India \\ ${ }^{4}$ Department of Chemical and Environmental Engineering, University of California, Riverside, \\ California 92521, USA \\ ${ }^{5}$ CSIR-National Physical Laboratory, Dr. K. S. Krishnan Road, New Delhi 110012, India
}

(Received 6 September 2014; accepted 9 November 2014; published online 24 November 2014)

\begin{abstract}
A specific and ultrasensitive, label free single-walled carbon nanotubes (SWNTs) based chemiresistive genosensor was fabricated for the early detection of Streptococcus pyogenes infection in human causing rheumatic heart disease. The mga gene of $S$. pyogenes specific 24 mer ssDNA probe was covalently immobilized on SWNT through a molecular bilinker, 1-pyrenemethylamine, using carbodiimide coupling reaction. The sensor was characterized by the current-voltage $(I-V)$ characteristic curve and scanning electron microscopy. The sensing performance of the sensor was studied with respect to changes in conductance in SWNT channel based on hybridization of the target S. pyogenes single stranded genomic DNA (ssG-DNA) to its complementary 24 mer ssDNA probe. The sensor shows negligible response to non-complementary Staphylococcus aureus ssG-DNA, confirming the specificity of the sensor only with $S$. pyogenes. The genosensor exhibited a linear response to $S$. pyogenes G-DNA from 1 to1000 $\mathrm{ng} \mathrm{ml}^{-1}$ with a limit of detection of $0.16 \mathrm{ng} \mathrm{ml}^{-1}$. (C) 2014 AIP Publishing LLC. [http://dx.doi.org/10.1063/1.4902447]
\end{abstract}

Bacterial Streptococcus pyogenes (S. pyogenes) infection in human throat causes initially pharyngitis and if it is not treated, it may cause damage of human heart valves and finally leads to rheumatic heart disease (RHD). ${ }^{1-3}$ RHD is a worldwide problem and it is more common in Asian developing countries due to poor health facilities. ${ }^{4-6}$ The usual detection methods of RHD infection are culture test, ${ }^{7}$ biochemical test $^{7,8}$ impedimetric immunosensor, ${ }^{9}$ multiplex PCR and genetic markers, ${ }^{10-12}$ illumigene kit assay ${ }^{13}$ and fluorescent in situ hybridization (FISH). ${ }^{14}$ All the above methods are time taking, less sensitive and specific, costly and non-confirmatory based on a single test. Even, PCR and marker based diagnosis take more time for confirmation of the infection of S. pyogenes. ${ }^{11,12}$ Therefore, there is a possibility of having an improved method of using a genosensor for an early detection of rheumatic heart disease. ${ }^{15}$ Nowadays, nanobiosensors are more demanding for rapid diagnosis of the disease because of portable, disposable, and a non-expensive label free detection technique with high sensitivity and specificity. Recently, the above features have been found in one-dimensional (1D) nanostructures (nanowires, nanotubes, and nanobelt) based chemiresistive/field effect transistors (FET) nanobiosensors due to their high sensitivity, ease of miniaturization, and low power requirement. Among these 1D nanostructures, single-walled carbon nanotubes (SWNTs) are extensively used as transducer due to their excellent electrical, chemical, and mechanical properties, ${ }^{16-18}$ for the development of label free nanosensors. The conductance of the SWNT chemiresistive/FET devices is highly sensitive to surface adsorption of biomolecules and is

\footnotetext{
a) Authors to whom correspondence should be addressed. Electronic addresses: rajesh_csir@yahoo.com and ashokigib@rediffmail.com
}

a function of analyte charge. ${ }^{19}$ Therefore, SWNT based chemiresistive genosensor may be an effective tool for an early detection of rheumatic heart disease.

$S$. pyogenes can be detected using mga (multiple gene activator) gene based specific probe, on SWNT chemiresistive device, which does not show homology with other pathogens or human DNA collected from patient throat swab samples. $m g a$ gene is the key regulator of virulence and conserved in Group A Streptococcus (GAS). ${ }^{20} m g a$, a $62 \mathrm{kD}$ DNA binding protein with 500 amino acids, ${ }^{21}$ is a multiple gene regulator which activates the transcription of several genes such as antiphagocytic M protein (emm), C5a peptidase $(s c p A), \mathrm{M}$-like proteins, and serum opacity factor (sof). ${ }^{22}$ Although, $m g a$ has various orthologs, it is conserved in $S$. pyogenes and hence can be used for the detection of $S$. pyogenes infection causing RHD in human.

Herein, we report the biofunctionalization of SWNT with a 24 mer $m g a$ capture probe through carboxyl $\left(5^{\prime} \mathrm{COOH}\right)$ to active amino group of an organic molecular bilinker, 1-pyrenemethylamine, on SWNT surface and its subsequent hybridization with the target $S$. pyogenes ssGDNA. A detail interaction of $S$. pyogenes ssG-DNA on SWNT upon hybridization was delineated using a nanoscale electronic chemiresistor device with SWNT acting as a semi-conducting channel.

Brain heart infusion broth was purchased from Himedia. Tris saturated phenol was obtained from Qiagen, Germany. $5^{\prime}$ carboxyl modified 24 mer capture $m g a$ gene ssDNA probe (5' HOOC-GCACAGCCAAT TTCTAGCTTGTCG 3') was chemically synthesized from Bio India Life Sciences, India. The SWNTs (SWNT-COOH, 80\%-90\% purity; bundle diameter: 4-5 nm) were purchased from Carbon Solution, Inc. (Riverside, CA). 


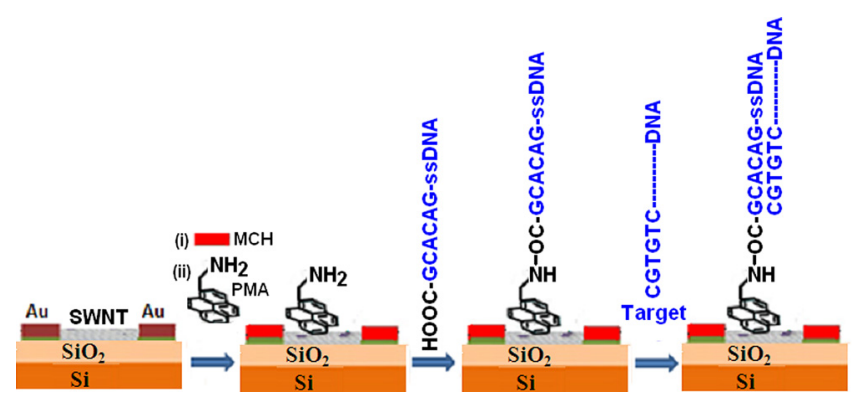

FIG. 1. Schematic representation for fabrication of SWNT genosensor for detection of RHD.

1-Ethyl-3-(dimethylaminopropyl) carbodiimide (EDC), $\mathrm{N}$ Hydroxysuccinimide (NHS) Tris(hydroxymethyl)aminomethane (Tris), ethylenediaminetetraacetic acid (EDTA), N, $\mathrm{N}^{\prime}$ dimethyl formamide (DMF), 6-mercaptohexanol (MCH), 1-pyrenemethylamine (PMA), and other chemicals were used without further purification. RHD patient swab samples were collected from Maulana Azad Medical College, Delhi, India. Bacterial culture and genomic DNA isolation were carried out by standard protocol, at National Centre for Disease Control (NCDC), Delhi, India.

The genomic DNA (G-DNA) isolation was carried out from $18 \mathrm{~h}$ cultured $S$. pyogenes from brain heart infusion broth at NCDC, Delhi using phenol chloroform method. ${ }^{23}$ The purity $\left(\mathrm{A}_{260 / 280}\right)$ and quantity $\left(\mathrm{A}_{260}\right)$ of the DNA was measured using nanodrop spectrophotometer.

The G-DNA was also isolated from throat swab of RHD patients by dissolving in $100 \mu \mathrm{l}$ STE $(50 \mathrm{mM}$ Tris, $50 \mathrm{mM}$ EDTA, 20\% Sucrose) buffer, pH 8 and heating at $95^{\circ} \mathrm{C}$ for 5 min (bacterial cell lysis). After cell lysis, it was centrifuged at $5000 \times \mathrm{g}$ for $5 \mathrm{~min}$ and supernatant (containing G-DNA) was taken for quantification by nanodrop spectrophotometer. The isolated DNA (dsDNA) after denaturation at $95^{\circ} \mathrm{C}$ for 5 min (ssDNA) was directly used for hybridization with immobilized ssDNA probe at SWNT.

The SWNTs $\left(0.01 \mathrm{mg} \mathrm{ml}^{-1}\right)$ were ultrasonically dispersed in $\mathrm{N}, \mathrm{N}^{\prime}$ dimethyl formamide (DMF) by centrifugation at $31000 \times \mathrm{g}$ for $90 \mathrm{~min}$. The dispersed SWNTs were aligned across a pair of the $3 \mu \mathrm{m}$ apart micro fabricated gold electrodes by ac-dielectrophoresis at applied frequency of $5 \mathrm{MHz}$ (1.5 V peak-to-peak amplitude). The aligned SWNTs were then annealed at $300^{\circ} \mathrm{C}$ for $1 \mathrm{~h}$ in a reducing environment ( $5 \% \mathrm{H}_{2}$ in $\mathrm{N}_{2}$ gas). The device was incubated with $6 \mathrm{mM}$ 6-mercapto-1-hexanol (MCH) in DMF for $1 \mathrm{~h}$ to passivate the gold surface (source and drain) in order to block the non-specific binding sites. The aligned SWNTs were incubated with $6 \mathrm{mM}$ 1-pyrenemethylamine (PMA) for $2 \mathrm{~h}$, at room temperature and were washed with DMF and dried under $\mathrm{N}_{2}$ gas flow. The single stranded $m g a$ gene ( $5^{\prime}$ carboxyl-GCACAGCCAATTTCTAGCTTGTCG 3') probe was covalently immobilized on SWNT by incubating it (10 $\mu \mathrm{M}$ in TE buffer; $\mathrm{pH} 8.0$ ) with SWNT-chip for $20 \mathrm{~h}$ at $37^{\circ} \mathrm{C}$. The chip was repeatedly washed with TE buffer to remove unbound probe and dried under $\mathrm{N}_{2}$ gas flow. The device (SWNT-chip) was further treated with $0.1 \%$ bovine serum albumin (BSA) to block the non-specific binding sites of both unreacted free $\mathrm{NH}_{2}$ sites of the crosslinker PMA as well as unexposed sites of SWNT, followed by washing with distilled water and dried under $\mathrm{N}_{2}$ gas flow to obtain the desired chemiresistive genosensor. The fabrication of chemiresistive genosensor is schematically represented in Fig. 1.

The sensor (device) characterization and sensing performance were carried out by monitoring the current-voltage $(I-V)$ characteristics between +0.5 and $-0.5 \mathrm{~V}$ (PGSTAT302N, AUTOLAB instrument from Eco Chemie, The Netherlands) and taking the inverse of the slope of the $I-V$ curve (resistance of the device). The SWNT-device was connected to a Micromanipulator model 450 PM-B probes station that makes electrical contact to the source and drain electrodes of the device. The $I-V$ measurements were taken after each step of device fabrication from SWNT alignment to $m g a$ ssDNA probe immobilization as shown in Fig. 2(a). The surface characterization of SWNT device, using scanning electron microscope, also confirms the alignment of SWNT between the pair of gold microelectrodes [inset of Fig. 2(a)]. Pristine SWNTdevice shows a $p$-type behavior [Fig. 2(b)] due to exposure of SWNTs to oxygen $\left(\mathrm{O}_{2}+2 \mathrm{e}^{-}=2 \mathrm{O}^{-}\right)$in a typically gate voltage dependence field effect transistor study with a back gate voltage, $V_{g}$, in the range of -40 to $+40 \mathrm{~V}$, at a drain voltage $\left(V_{d}\right) 0.1 \mathrm{~V}$ recorded on a Keithley semiconductor characterization system 2420. The current in the SWNT device, at given voltage decreased after passivation of the gold surface with non-specific blocking reagent $\mathrm{MCH}$, which may be attributed to the formation of self assembled monolayer (SAM) of MCH on the gold surface. Earlier, the formation of $\mathrm{MCH}$ at gold surface upon overnight exposure showed increased current in
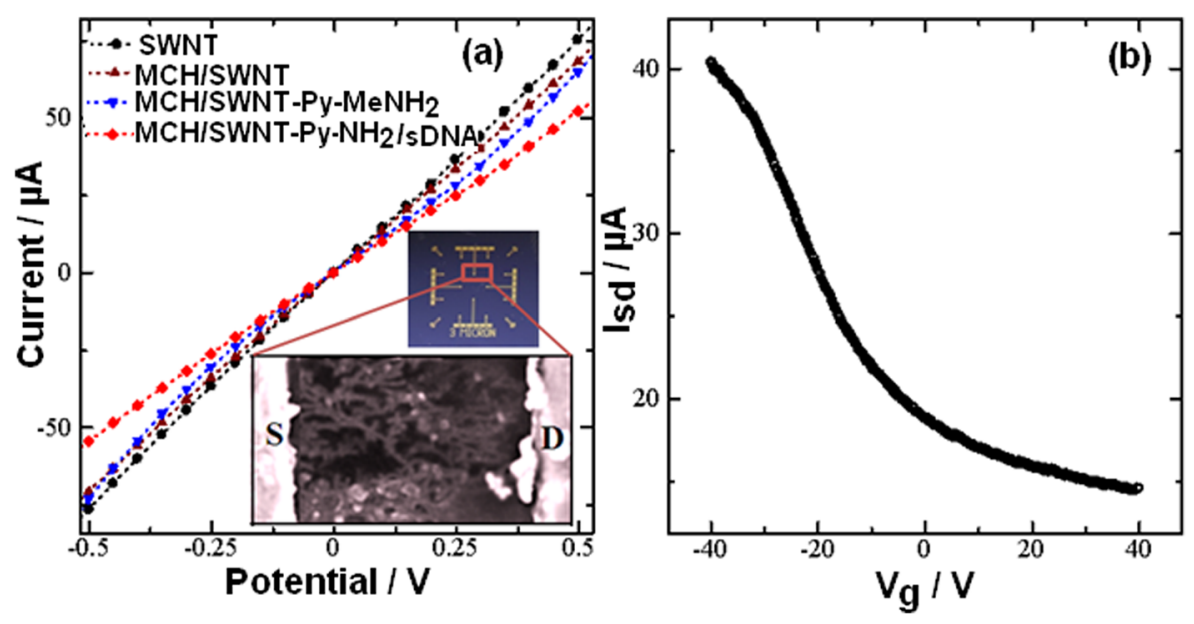

FIG. 2. (a) Current-Voltage (I-V) characteristics curve of the device at various stages of device fabrication; Inset shows the micro-chip structure with a SEM image of ssDNA probe-SWNT/ $\mathrm{Au}$ at $60.00 \mathrm{KX}$ magnification; (b) field effect transistor (FET) characteristics curve for the pristine SWNT/Au device. 


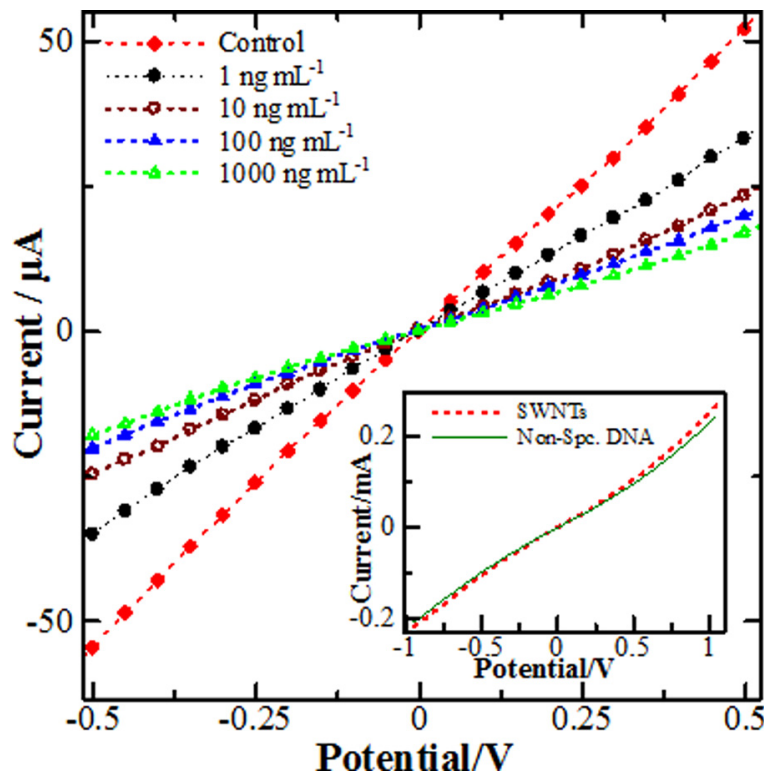

FIG. 3. The current-voltage $(I-V)$ characteristics of the device plotted between 0.5 and $-0.5 \mathrm{~V}$ for different concentrations $\left(1-1000 \mathrm{ng} \mathrm{ml}^{-1}\right)$ of hybridizing ssG-DNA with immobilized probe.

SWNT due to energy level alignment effect between the Au contact and SWNT ${ }^{24,25}$ that shifts the gold Fermi level towards the valence bond of SWNT and therefore, decreases the carrier injection barrier. However, a reverse trend of decreased current in SWNT observed in our case may be due to the short incubation time $(1 \mathrm{~h})$ of thiol that did not give enough time for thiol to diffuse into the SWNT gold interfaces. $^{26}$ The current in SWNT device further decreased (increased resistance) upon functionalization with a molecular biolinker, PMA, due to electron transfer to SWNT, confirming the attachment of PMA through $\pi-\pi$ stacking interaction between the SWNT and pyrene groups. A further decrease in current was observed in SWNT after covalent biomolecular immobilization with $m g a$ ssDNA gene probe. This change in conductance is in accordance with the literature ${ }^{27}$ and is attributed to the reduction in charge carriers (holes) in $p$-type SWNT semiconductor (increased resistance) due to accumulation of negative charge and/or scattering potential as a result of covalent attachment of ssDNA probe, thereby confirming the biofunctionalization of SWNT leading to the formation of the DNA sensor.

Sensing performance of the nanodevice was investigated for genomic DNA (G-DNA) isolated from $S$. pyogenes in TE buffer, $\mathrm{pH} 8$ and denatured at $95^{\circ} \mathrm{C}$ for 5 min to make single stranded genomic DNA (ss G-DNA) for hybridization with complementary single stranded DNA (ssDNA) probe on SWNT. $2 \mu \mathrm{l}$ sample of different concentrations of the target

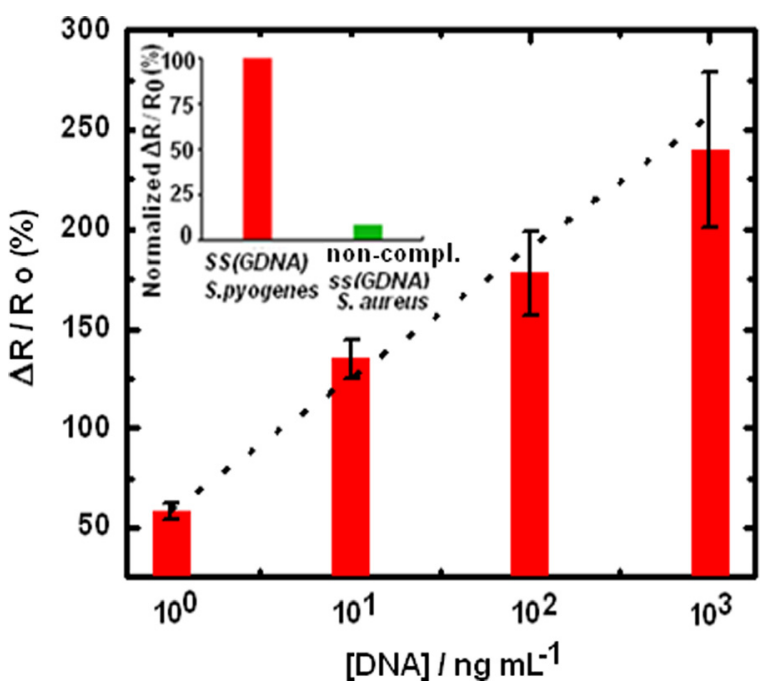

FIG. 4. Concentration dependence calibration curve of ssG-DNA probeSWNT/Au device for G-DNA of S. pyogenes. Each data point is an average of the measurements from three individual devices and error bars represent \pm 1 standard deviation; Inset: normalized $\Delta \mathrm{R} / \mathrm{R}_{0}(\%)$ response of the device for non-complementary (mismatch) G-DNA of $S$. aureus with respect to GDNA of S. pyogenes.

ssG-DNA in TE buffer was dispensed on the SWNT-device and washed off with TE buffer, $\mathrm{pH} 8$, after 2 min incubation, and $I-V$ characteristic curve was recorded from $-0.5 \mathrm{~V}$ to $+0.5 \mathrm{~V}$, under dry condition. Fig. 3 shows a decreasing trend in current in SWNT (increase in resistance) on successive incubation with an increasing concentration of ss-GDNA, confirming the sensing modality of the nanostructure chemiresistive genosensor for a small change in charge and/or size molecule upon hybridization. Fig. 4 shows the concentration dependent calibration plot for ssG-DNA with a relationship between the device normalized response $\left[\left(\mathrm{R}-\mathrm{R}_{0}\right) / \mathrm{R}_{0}\right.$, where $R_{0}$ and $R$ are the resistance of the device before (control) and after incubation with ssG-DNA] and ssG-DNA concentrations. The resistance was calculated as the inverse of the slope of the $I-V$ curve between -0.5 and $+0.5 \mathrm{~V}$ (linear range). The device exhibited a linear normalized response (normalized resistance change in percentage) to complementary ssG-DNA from 1 to $1000 \mathrm{ng} \mathrm{ml}^{-1}$ concentration with sensitivity (slope of the calibration curve) of $\sim 66 \%$. The error bars (which correspond to the change of resistance measured for 3 replicates) showed the variability of $\sim 6.7 \%$ in sensitivity over the concentration range of $1-1000 \mathrm{ng} \mathrm{ml}^{-1}$ ssG-DNA. The lowest detection limit (LOD) of the device was calculated from a formula $3 \sigma / \mathrm{m}$, where $\sigma$ is the standard deviation of control sample response and $m$ is the slope of the calibration curve and was found to be $0.16 \mathrm{ng} \mathrm{ml}^{-1}$ ssGDNA. This LOD of the SWNT-device is quite lower than

TABLE I. Comparative performance of different DNA based methods for detection of rheumatic heart disease (dsDNA: double stranded DNA, ssG-DNA: single stranded genomic DNA).

\begin{tabular}{|c|c|c|c|c|c|}
\hline S. No. & Detection method & Target & Limit of detection (LOD) & Detection time (min) & Reference \\
\hline 1 & speB genetic markers & dsG-DNA & 100 ng dsDNA & $80-120$ & 16 \\
\hline 2 & mga genetic marker & dsG-DNA & $100 \mathrm{ng}$ dsDNA & $80-120$ & 17 \\
\hline 3 & mga genosensor & ssG-DNA & $2.33 \mathrm{ng} \mathrm{ml}^{-1} \mathrm{ssDNA}$ & 30 & 27 \\
\hline 4 & Gold composite DNA sensor & ssG-DNA & $1.66 \mathrm{ng} \mathrm{ml}^{-1} \mathrm{ssDNA}$ & 30 & 28 \\
\hline 5 & Chemiresistive genosensor & ssG-DNA & $0.16 \mathrm{ng} \mathrm{ml}^{-1} \mathrm{ssDNA}$ & 5 & Present \\
\hline
\end{tabular}


earlier reported methods ${ }^{27,28}$ for $S$. pyogenes detection causing RHD, as shown in Table I.

The specificity of the SWNT-chemiresistive genosensor for ssG-DNA of S. pyogenes was investigated by incubating with noncomplementary ssG-DNA isolated from Staphylococcus aureus [inset of Fig. 3]. This experiment was conducted with a $10 \mathrm{ng} \mathrm{ml}^{-1} \mathrm{ssG}$-DNA (non-complementary), and the device response was compared to one obtained from a similar concentration of a complementary ssG-DNA of $S$. pyogenes [inset of Fig. 4], under identical conditions. Negligible current response was observed for the non-complementary ssG-DNA with a contribution of about $8.1 \%$ to the total response observed with respect to ssG-DNA of $S$. pyogenes for the same concentration, indicating a good selectivity and specificity of the sensor device. The performance of this device has been compared with different available methods with respect to LOD and the detection time for the detection of $S$. pyogenes causing RHD and is given in Table I.

In conclusion, a label free chemiresistive nanogenosensor device based on SWNT was developed for ultrasensitive early detection of $m g a$ gene of $S$. pyogenes causing RHD. The gene specific 24 mer ssDNA probe was covalently immobilized on SWNT for the construction of a chemiresistive genosensor. The hybridization event with complementary ssG-DNA of $S$. pyogenes was detected with a change in current in SWNT, at a concentration range of $1-1000 \mathrm{ng} \mathrm{ml}^{-1}$ with a sensitivity of $\sim 66 \%$ per decade and LOD of $0.16 \mathrm{ng} \mathrm{ml}^{-1}$. The high sensitivity, specificity, and label free technique makes this chemiresistive genosensor advantageous over the previous methods for early detection of RHD to prevent the damage of mitral and aortic heart valves.

Swati Singh thanks CSIR, New Delhi for providing fellowship to carry out the research work. Dr. Rajesh is thankful to Professor R. C. Budhani, Director, NPL, New Delhi, India, for providing facilities.

${ }^{1}$ R. S. Vasan, S. Shrivastava, M. Vijayakumar, R. Narang, B. C. Lister, and J. Narula, Circulation 94, 73 (1996).
${ }^{2}$ M. W. Cunningham, Clin. Microbiol. Rev. 13, 470 (2000).

${ }^{3}$ A. L. Bisno, M. O. Brito, and C. M. Collins, Lancet Infect. Dis. 3, 191 (2003).

${ }^{4}$ J. R. Carapetis, A. C. Steer, E. K. Mulholland, and M. Weber, Lancet Infect. Dis. 5, 685 (2005).

${ }^{5}$ G. Günther, J. Asmera, and E. Parry, Lancet 367, 391 (2006).

${ }^{6}$ J. R. Carapetis, Circulation 118, 2748 (2008).

${ }^{7}$ J. A. Freiberg, K. S. McIver, and M. E. Shirtliff, Infect. Immun. 82, 3891 (2014).

${ }^{8}$ A. L. Bisno, M. A. Gerber, J. M. Gwaltney, E. L. Kaplan, and R. H. Schwartz, Clin. Infect. Dis. 25, 574 (1997).

${ }^{9}$ A. Ahmed, J. V. Rushworth, J. D. Wright, and P. A. Millner, Anal. Chem. 85, 12118 (2013).

${ }^{10}$ A. L. Borek, K. Obszańska, W. Hryniewicz, and I. Sitkiewicz, Virulence 3, 529 (2012).

${ }^{11}$ A. Kaushal, D. Kumar, S. Khare, and A. Kumar, Cell Mol. Biol. 58(1), 50 (2012).

${ }^{12}$ K. Goyal, R. Chitransh, S. Khare, R. Chaudhary, and A. Kumar, J. Biosci. Med. 2(1), 1 (2012).

${ }^{13}$ N. W. Anderson, B. W. Buchan, D. Mayne, J. E. Mortensen, T. L. Mackey, and N. A. Ledeboer, J. Clin. Microbiol. 51, 1474 (2013).

${ }^{14}$ S. Tajbakhsh, S. Gharibi, K. Zandi, R. Yaghobi, and G. Asayesh, Eur. Rev. Med. Pharmacol. Sci. 15, 313 (2011).

${ }^{15}$ P. Hui, Z. Lijuan, S. Christian, and T. S. Jadranka, Biomaterials 30, 2132 (2009).

${ }^{16}$ H. Cai, X. Cao, Y. Jiang, P. He, and Y. Fang, Anal. Bioanal. Chem. 375(2), 287 (2003).

${ }^{17}$ K. Kerman, Y. Morita, Y. Takamura, and E. Tamiya, Anal. Bioanal. Chem. 381(6), 1114 (2005).

${ }^{18}$ K. Balasubramanian and M. Burghard, Anal. Bioanal. Chem. 385(3), 452 (2006).

${ }^{19}$ L. N. Cella, W. Chen, N. V. Myung, and A. Mulchandani, J. Am. Chem. Soc. 132, 5024 (2010).

${ }^{20}$ E. R. Hondorp and K. S. McIver, Mol. Microbiol. 66, 1056 (2007).

${ }^{21}$ K. S. Mclver, A. S. Thurman, and J. R. Scott, J. Bacteriol. 181(17), 5373 (1999).

${ }^{22}$ M. Louie, L. Louie, and A. E. Mimor, Can. Med. Assoc. J. 63(3), 301 (2000).

${ }^{23}$ S. Singh, A. Kaushal, S. Khare, and A. Kumar, Appl. Biochem. Biotechnol. 173, 228 (2014).

${ }^{24}$ X. Tang, S. Bansaruntip, N. Nakayama, Y. Yenilmez, Y. L. Chang, and Q. Wang, Nano Lett. 6, 1632 (2006).

${ }^{25}$ X. Cui, M. Freitag, R. Martel, L. Brus, and P. Avouris, Nano Lett. 3, 783 (2003).

${ }^{26}$ E. S. Forzani, X. Li, P. Zhang, N. Tao, R. Zhang, I. Amlani, R. Tsui, and L. A. Nagahara, Small 2, 1283 (2006).

${ }^{27}$ G. Gruner, Anal. Bioanal. Chem. 384, 322 (2006).

${ }^{28}$ S. Singh, A. Kaushal, S. Khare, P. Kumar, and A. Kumar, Analyst 139, 3600 (2014) 